\title{
Ocio, recreación e interculturalidad desde el "Sur" del mundo: desafíos actuales*
}

\author{
Christianne Gomes**
}

\begin{abstract}
Resumen: Este artículo tiene por objetivo ampliar la reflexión crítica sobre el ocio y la interculturalidad en América Latina. La discusión fue basada en una investigación bibliográfica y tiene como telón de fondo el repensar la modernidad, la ideología de progreso y las dicotomías que limitan las concepciones de ser humano y de mundo. El texto propone, además, discutir el potencial del ocio para enriquecer las prácticas educativas a partir de distintos lenguajes, teniendo en vista el caminar en dirección de una educación intercultural que sea también problematizadora, crítica y transformadora. En cuanto una dimensión de la cultura, el ocio puede ser un tiempo/espacio social de resignificación y empoderamiento, contribuir para agudizar sensibilidades y ayudar a la comprensión de los contextos latinoamericanos en la perspectiva de la interculturalidad, estimulando el pensamiento crítico sobre las sociedades para la transformación social en búsqueda de un mundo más humano y solidario.

Palabras clave: Ocio, recreación, interculturalidad, América Latina, educación transformadora.
\end{abstract}

\section{Leisure, recreation and interculturalism from the "South" of the world: current challenges}

\begin{abstract}
This article aims to expand critical analysis on leisure and interculturality in Latin America. The discussion was based on a bibliographic search and analyzes modernity, the ideology of progress and the dichotomies that limit the conceptions on human beings and the world. The text also proposes to discuss the potentiality of leisure to enrich the educational practices arising from different languages, considering the relevance of intercultural, critical and transformative education. As a dimension of culture, leisure can be a social time-space of resignification and empowerment, helping to stimulate sensibilities and help the understanding of Latin American context in an intercultural perspective, encouraging a critical thinking about societies, in the search for social transformation, committed to the building of a humane and solidary world.
\end{abstract}

Key-words: Leisure, recreation, interculturality, Latin America, transformative education.

\section{Lazer, recreação e interculturalidade a partir do "Sul" do mundo: desafios atuais}

Resumo: O presente artigo tem como objetivo aprofundar a reflexão crítica sobre lazer e interculturalidade na América Latina. A discussão foi baseada em uma revisão de literatura e tem como pano de fundo o repensar da modernidade, a ideologia do progresso e as dicotomias que limitam as nossas concepções de homem e de mundo. $\mathrm{O}$ texto também propõe discutir o potencial do lazer para enriquecer as práticas educativas a partir de diferentes linguagens, tendo em vista caminhar em direção a uma educação intercultural, que seja também problematizadora, crítica e transformadora. Como uma dimensão da cultura, o lazer pode ser um tempo/espaço social de ressignificação e empoderamento, contribuindo para aguçar as sensibilidades e ampliar a compreensão sobre os contextos latino-americanos na perspectiva da interculturalidade, estimulando o pensamento crítico sobre as sociedades para a transformação social na busca de um mundo mais humano e solidário.

Palavras-chave: Lazer; Recreação; Interculturalidade; América Latina; Educação Transformadora.

Recibido: 15.06 .2010

Aceptado: 07.07.2010

$$
* * *
$$

\section{Introducción}

Para discutir el tema de este artículo se propone una reflexión sobre la realidad concreta para, en seguida, explorar algunas facetas del ocio ${ }^{1}$, de la recreación y de la interculturalidad, aquí concebidos como elementos que pueden contribuir significativamente para promover una educación por la transformación social en las distintas ciudades y países de América Latina, avanzando en la construcción de una sociedad más justa y digna. 
Esta esencial reflexión podría ser hecha desde diversas estrategias. En este artículo se pretende iniciarla abriendo caminos por senderos que articulan sensibilidad poética y crítica social sobre las realidades latino-americanas. Varias obras pueden estimular a recorrer estos caminos, como el libro Canto General, del poeta chileno Pablo Neruda (2005). Esta obra fue publicada originalmente en 1950, época en que Neruda es obligado a abandonar su patria y vivir el exilio político en otros países, marca de los tiempos tristes (y no muy distantes) de la persecución política que asoló, poco a poco, varios países latino-americanos, sobretodo en las fases de dictaduras militares y gobiernos autoritarios.

Los versos de Neruda revelan el dolor de quién constata las injusticias sociales existentes en la realidad latino-americana. El autor consigue crear con maestría, evidenciando que su obra es fruto de inspiración poética impulsada por un significativo trabajo de estudio, investigación, reflexión crítica y consciencia en cuanto sujeto político e histórico. Esta obra es llena de notable belleza y sensibilidad histórica, geopolítica, social, cultural y ecológica.

El "yo poético" de Neruda pone en evidencia detalles de la tierra y de la historia latinoamericana, las cuales revelan la esencia de un contexto que, en el comienzo de este siglo XXI, aún se conoce poco y, no raras veces, de manera parcial, limitada y distorsionada. En este sentido, sus poemas hablan sobre naturalezas y culturas destrozadas, sobre historias oficiales y otras silenciadas; sobre tiempos y espacios varios; sobre conquistadores y libertadores, dictadores y héroes populares; países y pueblos subyugados; rebeliones, resistencias, masacres y solidaridades, victorias y derrotas, entre tantos otros temas tratados por Neruda en el sentido de trascender la realidad inmediata con mucha propiedad, sabiduría y consciencia política.

No es casual que el poema que abre el libro lleve por título "Amor América (1.400)" y, en este, el lector es invitado a hacer un viaje que tiene como punto de partida una realidad anterior a la llegada de los conquistadores españoles y portugueses (seguidos de los ingleses, franceses y holandeses) a este continente. Como ejemplo, puede ser citada una parte del poema "Los nuevos propietarios" (Neruda, 2005, p.105-106).

\section{Los nuevos propietarios}

(Pablo Neruda)

“Así se estancó el tiempo en la cisterna.

El hombre dominado en las vacías encrucijadas, piedra del castillo, tinta del tribunal, pobló de bocas la cerrada ciudad americana.

Cuando ya todo fue paz y concordia, hospital y virrey, cuando

(...)

era la rata el único peligro

de las tierras encarnizadas, se asomó el vizcaíno con un saco,

el Errázuriz con sus alpargatas,

el Fernández Larraín a vender velas, el Aldunate de la bayeta,

el Eyzaguirre, rey del calcetín.

Entraron todos como pueblo hambriento, huyendo de los golpes, del gendarme.

Pronto, de camiseta en camiseta, expulsaron al conquistador y establecieron la conquista del almacén de ultramarinos. Entonces adquirieron orgullo 
comprado en el mercado negro.

Se adjudicaron

haciendas, látigos, esclavos,

catecismos, comisarías,

cepos, conventillos, burdeles,

y a todo esto denominaron

santa cultura occidental."

En este poema, las metáforas subyacentes a las paradojas destacadas por Neruda pueden suscitar varias interpretaciones, reflexiones y preguntas:

¿De qué manera, y a partir de cuales principios, los pueblos y las ciudades latinoamericanas vienen "desarrollándose", "progresando" y "modernizándose"? Incluso después de la independencia de las antiguas colonias americanas ¿Porqué las prácticas de dominación continúan siendo ejercidas entre nosotros y por nosotros? ¿Porqué ellas legitiman nuevos conquistadores y propietarios a partir de la centralidad de la economía basada en la explotación y en relaciones desiguales? ¿Qué papel América Latina asume en este juego de poder? ¿Qué podemos entender por "cultura occidental” y porqué, cada vez más, el mercado comprometido con los intereses de los grupos privilegiados se afirma como elemento fundante de esa ideología?

Para ampliar la percepción crítica sobre estas preguntas, es necesario repensar los discursos sobre la "modernidad", el "desarrollo" y el "progreso" que modelan la "santa cultura occidental". Estos elementos, en conjunto, naturalizan relaciones sociales, mantienen el orden global instituido - que conviene apenas a los segmentos privilegiados de los diversos países del mundo - y garantiza la perpetuación y el avance del capitalismo neoliberal, indicando que a pesar del colonialismo haber finalizado con la independencia de las ex-colonias latino-americanas, la "colonialidad" continua perpetuándose en el siglo XXI.

\section{América Latina y modernidad: Pueblos, culturas y países ¿Al servicio de quién, por qué y para qué?}

Las bases ideológicas de la modernidad son, generalmente, localizadas en Europa como consecuencia de tres movimientos principales: la reforma, la ilustración y especialmente la revolución industrial vivida en los principales centros urbanos, sobre todo capitalistas. En otras palabras, únicamente los fenómenos europeos son considerados decisivos para el inicio de la modernidad.

Como muestra Dussel (2005), esta visión establece y reconoce exclusivamente fenómenos “intraeuropeos" como punto de partida para la modernidad. En esta perspectiva, se considera que el desarrollo posterior al paradigma de la modernidad necesita solamente de Europa para explicar este proceso. Para el autor, esta visión de modernidad es ampliamente adoptada, tanto en la vida cotidiana como en el campo académico, siendo reforzada por diversos autores, dentro de ellos Weber (1973) y Habermas (2000).

Esta forma de comprender la modernidad precisa de ser repensada. Se trata de un paradigma que, además de ser centrado en Europa, excluye la decisiva participación de otras realidades en un juego de poder que envuelve, de manera desigual, varios componentes, dentro de los cuales los pueblos y culturas de los otros continentes, como América Latina, África, Oceanía y Asia. La revolución industrial, por ejemplo, fue un fenómeno que impulsó el desarrollo de los centros urbanos europeos. Pero ¿Cómo fue posible la ocurrencia de este acontecimiento en Europa?

Galeano (2009) explica que el valor del capital invertido en todas las industrias europeas hasta el año 1800 fue muy pequeño en relación a la gigantesca masa de capitales generada desde las primeras etapas de explotación de América Latina: con los metales preciosos y materias primas, con el trabajo esclavo y, a su vez, con el lucro generado por el tráfico de esclavos africanos, todo esto solamente en los siglos XVI-XVII.

España y Portugal no se quedaron con los mayores beneficios del avance del mercantilismo capitalista, mismo que fuesen sus colonias las que, en gran parte, proporcionaron el oro y la plata que alimentaban la 
expansión de este sistema. Fueron otras las comarcas de Europa que pudieron incubar el capitalismo moderno, valiéndose, en gran parte, de la expropiación de riquezas y explotación los pueblos nativos de América. Esto permitió que la emergente clase burguesa se apoderase de las ciudades y fundase bancos; produciendo e intercambiando mercancías, conquistando así nuevos mercados. Los recursos fluían desde América para que las emergentes naciones europeas acumulasen capitales del otro lado del océano. (Galeano, 2009)

La América ingresó dentro del capitalismo comercial de una forma muy ágil, contribuyendo para dar a este ciclo un vigor colosal y tornando posible el surgimiento del capitalismo industrial algunos años después (Bagú, 1993). Así, se creó un ambiente favorable para varios países colonialistas e imperialistas, lo que financió el establecimiento de fábricas (sobre todo en Inglaterra), dando un gran impulso a la revolución industrial.

De esta forma, las colonias americanas fueron descubiertas, conquistadas y colonizadas dentro del proceso de expansión del capital comercial europeo, siendo ellas imprescindibles para la constitución de la modernidad, entendida como un nuevo momento histórico, social, cultural, económico y político que involucró distintos sujetos, naciones y continentes del mundo.

Por las ideas recién planteadas, es pertinente la teoría de Dussel (2000): la modernidad subsumida de un horizonte mundial tiene como importante marco el año de 1492, con la conquista del Atlántico y el desarrollo del mercantilismo capitalista, permitiendo a los países colonizadores de Europa una extraordinaria acumulación de riqueza monetaria -elementos que entregan las condiciones históricas y sociales fundamentales para la constitución de la era moderna desde un ponto de vista más ampliado, que extrapola las fronteras del continente europeo. Los estudios del autor muestran que hasta el siglo XV la Europa Latina era una cultura periférica, secundaria, aislada y sitiada por el mundo musulmán. Además de eso, esa designación -"Europa"- solo pasó a ser utilizada con un sentido continental en el siglo XVIII, como un claro esfuerzo para reforzar el imaginario sobre la existencia de una unidad entre los países imperialistas, fortaleciéndolos y destacándolos aún más frente a los otros continentes.

Como señalan diversos autores latino-americanos (Quijano, 2000; Mignolo, 2000; Dussel, 2000, Lander, 2000), no se puede hablar de modernidad sin considerar las relaciones de poder constituidas por medio de la colonialidad. Esta es la "cara oculta", u "otro lado" silenciado y encubierto de la modernidad y también de la llamada "post-modernidad" que acaba reforzándola. Sobre este aspecto, es importante recordar las palabras de Mignolo (2000:7): "El imaginario del mundo moderno/colonial surgió de la compleja articulación de fuerzas, de voces escuchadas o apagadas, de memorias compactas o fracturadas, de historias contadas de un solo lado, que suprimieron otras memorias (...).”

Los indígenas americanos, por ejemplo, fueron considerados por los colonizadores "animales sin dueños", "animales débiles", "perezosos y estúpidos" y sin "ninguna actividad del alma". Por eso ellos afirmaban que el trabajo forzado era el mejor remedio para curar la "maldad natural" de los indios. Ellos "merecían los tratos que recibían porque sus pecados e idolatrías constituían una ofensa a Dios" (Galeano, 2009:61), además de no tener gratitud con los conquistadores por todo el bien que les hicieron. Es así que las crueldades sufridas por los amerindios y, posteriormente, por los millones de africanos esclavizados y traficados hacia América, fueron ampliamente justificadas por los explotadores, que tenían las bendiciones papales para seguir con su noble misión de catequizar a los paganos $\mathrm{y}$, en consecuencia, negar y destruir sus culturas. $(2005: 7)$

En este ámbito, son curiosas las dos interpretaciones que fueron sabiamente asociadas por Dussel

En la obra de Tzvetan Todorov, Nosotros y los os otros (1991), el "nosotros" corresponde a los europeos, y los "otros" somos nosotros, los pueblos del mundo periférico. La modernidad se definió como "emancipación" en lo que dice respecto a "nosotros", más no percibe su carácter míticosacrificial con relación a los "otros". Montaigne (1967, p.208) de algún modo lo percibe cuando afirmó: Así, podemos llamarlos bárbaros con relación a nuestras reglas de la razón, pero no con relación a nosotros mismos, que los superamos en todo género de barbarie. 
Lamentablemente, no siempre prevalece la lucidez expresada por Montaigne en esta cita de su obra Los caníbales, publicada originalmente en 1580. Así, las prácticas culturales de los amerindios y de los africanos traficados como esclavos y traídos en esta condición para las Américas a partir del siglo XVI, por ejemplo, eran extremamente distintas de aquellas valorizadas por los colonizadores. Este encuentro/enfrentamiento podría dar inicio a un proceso de diálogo cultural, pero esto no aconteció: las prácticas culturales amerindias y africanas eran consideradas inferiores, bárbaras, salvajes, primitivas y atrasadas en contraposición/comparación con la(s) cultura(s) de los conquistadores españoles y portugueses, las que son percibidas como modernas, avanzadas, válidas, legítimas, universales y desarrolladas.

El encuentro entre los conquistadores y los mayas, los aztecas y los incas, por ejemplo, no permitió el reconocimiento y la valoración de las grandezas de estas sociedades nativas, como las invenciones técnicas, la arquitectura, los monumentos religiosos, los objetos de arte, los canales de irrigación y cultivos agrícolas, los conocimientos matemáticos, de medicina y astronomía, sus juegos, fiestas y otras tradiciones culturales. Todo esto fue visto como primitivo y pagano, teniendo que seguir un largo camino lineal hasta un punto superior, donde los conquistadores europeos pensaban estar ubicados.

Con lo anterior, no se pretende idealizar a los pueblos y culturas indígenas y africanos, sino poner en evidencia que la consideración de primitivos y atrasados, de los conquistadores hacia los pueblos no europeos es falsa e injusta. Además, generó una práctica discursiva ideológica que, desde el momento del "descubrimiento" de América, hizo que los españoles (seguidos de los portugueses y otros) se considerasen superiores a los nativos, instaurando así una diferencia fundamental desde un punto de vista ontológico: los exploradores/colonizadores eran naturalmente superiores, en su ser, teniendo así el poder de dominar a los "salvajes", inferiores por naturaleza. De ahí derivó la idea que, siendo dóciles y (en un primero momento) receptivos a los conquistadores, los amerindios serían óptimos trabajadores serviles, pues, la base de esa inferioridad se colocaba en la propia constitución de esos sujetos en cuanto seres humanos con poco o sin valor. Nada había que discutir: la diferencia supuestamente existente entre ellos era de raíz ontológica: por lo tanto, incuestionable.

En los días de hoy es posible constatar la fuerza y la eficacia neutralizadora de esa ideología que, lamentablemente, se viene perpetuando a lo largo de los siglos e interfiere en todas nuestras prácticas, incluso en muchas vivencias de recreación que imponen formas estereotipadas y homogéneas de diversión y entretenimiento que contribuyen a reforzar la discriminación y exclusión sociocultural. Esta ideología postula que algunos seres son inferiores y otros superiores en su propia esencia, algo utilizado para justificar las jerarquías, la dominación y la violencia. En esta perspectiva, los discursos en torno de la supremacía masculina y la idea de raza necesitan ser cuestionados. Esos discursos fueron forjados para legitimar relaciones de dominación y de explotación del hombre blanco sobre los/las "no blancos/as", haciendo que el racismo y el sexismo (entre otros "ismos") se perpetúen por todo nuestro planeta. En el caso de la idea de raza, su premisa fundamental -jerarquización de supuestas diferencias raciales- no tienen ninguna sustentación desde un punto de vista biológico, pues, la "raza" humana es una sola. El concepto de raza significa "una construcción discursiva histórica cuyo uso evidencia relaciones de fuerza y de dominación que existen dentro de una sociedad", como recuerda Goellner y colaboradores (2009:14).

Las prácticas discursivas históricamente construidas en las realidades latinoamericanas también tomaron otras facetas. Forjadas sobre el discurso acerca del desarrollo, se observa que la modernidad capitalista consagró su excelencia a partir del progreso técnico, materializado en el avance del dominio del hombre sobre la naturaleza como si él estuviese separado de ella, en una relación de competencia. Según Grangeiro (2009), esa visión de mundo considera progreso histórico al dominio de la naturaleza por el hombre, culminando en una ideología que concibe las relaciones sociales apenas en función de sus realizaciones técnicas abstractas, mensuradas en términos de contabilidad monetaria. Con esto, históricamente, fue impuesta una forma de sociabilidad en la cual las relaciones sociales se objetivan en la forma de una economía mercantil generalizada. De esa manera, la satisfacción de las necesidades humanas, necesariamente, pasa a ser mediada por el mercado y sus componentes (valor de cambio, mercadería, dinero, capital, lucro).

Esta concepción se afirmó con la revolución industrial europea del siglo XIX y fue potencializada con el avance científico-tecnológico sobre todo en el siglo siguiente, basada en la creencia de que la ciencia y la 
tecnología solucionaran todas las problemáticas y efectos indeseables del sistema (Elizalde, 2008). Este aspecto dinamizó las estrategias de crecimiento económico de las industrias capitalistas desde Europa, seguida de los Estados Unidos que, hoy, tienen un poder muy amplio sobre Latinoamérica, ejerciendo otro tipo de subyugación protagonizada por el mercado -que se presenta tras su disfraz de social, libre y democrático.

Los antiguos conquistadores son ahora los tecnócratas en sus aviones privados, los cobradores de los impuestos del reino fueron sustituidos por los burócratas financistas del Fondo Monetario Internacional y del Banco Mundial, los traficantes de esclavos son hoy los defensores de los lucros privados de las grandes corporaciones transnacionales, como denunciaba Galeano (2009) en los años de 1970.

Este proceso tiene, cada vez más, variadas y perversas implicaciones: sociales, económicas, políticas, culturales e incluso ecológicas, con consecuencias dramáticas y, en muchos casos, irreversibles. Desde que la producción continúe creciendo, poco importa si la miseria, el hambre, el desempleo, la pobreza, la concentración de riqueza, la desigualdad y la exclusión continúen aumentando. De igual modo, poco importa si los bosques son talados, la biodiversidad destruida y la vida de todo el planeta colocada en peligro, llevándonos a una situación de real emergencia planetaria. Eso requiere cuestionar la ideología de crecimiento como algo positivo en todos los sentidos, como advierte Elizalde (2010). Al final ¿Cuales son los costos socio-ambientales de este pseudo-desarrollo que acostumbramos llamar de "progreso"?

Siguiendo esta discusión, podemos cuestionar también la clasificación de las naciones del mundo en desarrolladas y no desarrolladas, subdesarrolladas o en desarrollo, teniendo como única referencia el modelo socioeconómico vigente en los países que ocupan posición de hegemonía en la división internacional del trabajo y en el mercado mundial. Galeano (2009) considera que existen solo dos lados en esta división político-económica: en uno, están los países que se especializan en ganar y en el otro, los que se especializan en perder, como la mayoría de los países latinoamericanos. Es así que, en muchos casos, América Latina trabaja para otros y no para el propio bien estar de sus pueblos. Así, esta región:

Continúa existiendo al servicio de necesidades ajenas, como fuente y reserva de petróleo y fierro, cobre y carne, frutas y café, materias primas y alimentos destinados a los países ricos que ganan, consumiéndolos, mucho más de lo que la América Latina gana produciéndolos. Son mucho más altos los impuestos que cobran los compradores que los precios que reciben los vendedores (...). (Galeano, 2009:17)

Según Gadotti (2000:59), “[...] desarrollo no es un concepto neutro. Él tiene un contexto bien preciso dentro de una ideología de progreso, que supone una concepción de historia, de economía, de sociedad y del propio ser humano". Esta visión es representativa de los intereses capitalistas y neoliberales y desconsidera el hecho de que esa forma de sociabilidad no es la única posible. Además de las estrategias basadas en la explotación y dominación, siempre existieron formas alternativas y solidarias de realizar socialmente el intercambio de los seres humanos con la naturaleza. No siempre la forma de vínculo social asume la forma de una relación mercantil en la cual el frío interés se convierte en norma de conducta social (Grangeiro, 2009).

No olvidemos que los países hegemónicos, como los países ricos de Europa y los Estados Unidos, desde el momento en que se establecieron como epicentro y culminación del ideal de progreso, son tomados como referencia universal. Esto supuesto progreso fue posible gracias a una acción explotadora de los seres humanos y de las riquezas naturales generadas en/por las (ex)colonias que hoy, no por casualiadad, constituyen el bloque planetario de los países del "Sur" (geo-económico-político), de las naciones empobrecidas clasificadas como tercer mundo y rotuladas como subdesarrolladas y atrasadas, cuya población está muy distante del ideal de ser humano: blanco, europeo y cristiano. En este proceso, los pueblos de distintos países de América Latina hasta perdieron su derecho de ser llamados americanos, como destaca Galeano (2009). La América es, para el mundo, nada más que los Estados Unidos: nosotros habitamos una sub-américa, una América de según clase, de nebulosa identificación y que lamentablemente sigue funcionando como "patio trasero" para los Estados Unidos.

En este proceso, un elemento fue y sigue siendo primordial: los mecanismos de explotación adoptados por los propios latinoamericanos que lucran con este sistema neoliberal, de carácter político, social y 
económico desigual e injusto. Las clases privilegiadas de América Latina y las oligarquías financieras nacionales que concentran el poder económico y en la mayoría de los casos también el poder político, son los guardianes del sistema, ubicando al mercado en el centro de las decisiones medulares de las naciones de nuestra región. Con esto los mercadores de la "santa cultura occidental", denunciados en el poema de Neruda, permanecen intocables.

Además, con la importación de los saberes europeos, combinados con el estilo de vida norteamericano, el mundo pasa a ser visto como un gran centro comercial donde todo está en venta para ser consumido, incluso el ocio y la cultura, homogenizando gustos y preferencias, y haciéndonos creer que en el acto de consumo podremos ascender a un nivel cultural más elevado, avanzado, evolucionado y moderno (Gomes, 2008). ¿Cómo este proceso involucra el ocio y la educación en las culturas latinoamericanas?

\section{Hacia la interculturalidad: Un desafío para el ocio/educación en América Latina}

Algunos conceptos procuran rescatar la pluralidad y la diversidad que debe orientar los debates sobre el tema de la cultura, como el multiculturalismo y el hibridismo cultural. Estos conceptos son interesantes, pero en muchos casos son insuficientes para enfrentar los desafíos verificados en nuestras realidades latinoamericanas.

Hall (2003) identifica, en la actualidad, al menos seis concepciones diferentes de multiculturalismo: (1) Multiculturalismo conservador: los dominantes buscan asimilar las minorías diferentes a las tradiciones y costumbres de la mayoría; (2) Multiculturalismo liberal: los diferentes deben ser integrados como iguales en la sociedad dominante. La ciudadanía debe ser universal e igualitaria, pero en el dominio privado los diferentes pueden adoptar sus prácticas culturales específicas; (3) Multiculturalismo pluralista: los diferentes grupos deben vivir separadamente, dentro de un orden político federativo; (4) Multiculturalismo comercial: la diferencia entre los individuos y grupos debe ser resuelta en las relaciones de mercado y en el consumo privado, sin que sean cuestionadas las desigualdades de poder y de riqueza; (5) Multiculturalismo corporativo (público o privado): la diferencia debe ser administrada, de modo a que los intereses culturales y económicos de las minorías subalternas no molesten los intereses de los dominantes; (6) Multiculturalismo crítico: cuestiona el origen de las diferencias, criticando la exclusión social, la exclusión política, las formas de privilegio y de jerarquía existentes en las sociedades contemporáneas. Apoya los movimientos de resistencia y de rebelión de los dominados.

El multiculturalismo es válido porque reconoce la existencia de culturas diferentes al negar una cultura única, pero mismo su vertiente crítica -que denuncia jerarquías y exclusiones, y valora los movimientos de resistencia- no avanza en términos de generar diálogos y integraciones más consistentes y críticos entre las distintas culturas.

El concepto de hibridismo, por su vez, para García Canclini (1997) denomina procesos socioculturales donde las estructuras o prácticas que existían de forma separada son combinadas para generar nuevas estructuras, objetos y prácticas que son ahora nuevas mesclas. Este abordaje reconoce que la hibridación no es sinónimo de fusión sin contradicción, que este proceso no es espontaneo al involucrar relaciones de poder que interesan a los sectores hegemónicos.

De manera general, el concepto de hibridismo falla al reforzar las nociones de tradicional y moderno en cuanto partes secuenciales de un tiempo histórico normal, lineal y universal, que sigue siendo la referencia válida para otras temporalidades y realidades, incluso para las latinoamericanas. Al desconsiderar otras temporalidades, el concepto de hibridismo revela uno de sus puntos ciegos.

Así como el multiculturalismo y el hibridismo, las distintas estrategias presentadas y criticadas en el tópico anterior desconsideran la simultaneidad de culturas, sociedades, valores y tiempos/espacios sociales de/en América Latina. Así, predominan prácticas, representaciones y conceptos hegemónicos. Esta norma civilizatoria tenida como válida, natural, universal y superior concibe otras culturas como atrasadas y poco evolucionadas. Entre tanto, Lander (2000:8) advierte: Al caracterizar las expresiones culturales como "tradicionales" o "no modernas", como en proceso de transición en dirección a la modernidad, se les niega 
toda posibilidad de lógicas culturales o cosmovisiones propias. Al colocarlas como expresión del pasado, se niega su contemporaneidad.

Partiendo de este presupuesto, muchas prácticas culturales fueron/son subvaloradas y menospreciadas; muchos aspectos importantes de la historia latinoamericana fueron/son silenciados y muchos procesos fueron y continúan siendo mutilados y desterrados. Las personas pasan a creer que existen solo dos culturas: una de ellas es la moderna, la avanzada y la cierta; la otra, a su vez, es un bloque compuesto por incontables culturas latinoamericanas, vistas como atrasadas, primitivas, salvajes y no ciertas. Esta creencia es una falacia.

Ayer, hoy y siempre es imprescindible develar los conflictos del presente y buscar la transformación social en el sentido de valorar y promover diálogos fructíferos entre las incontables culturas de Latinoamérica, teniendo en cuenta el desafío de reducir las desigualdades económico-sociales, buscar la equidad y la justicia social. Es necesario, así, comprometernos con la constitución de prácticas culturales/educativas basadas en relaciones de reciprocidad, y no de jerarquización. Esa tarea demanda, inicialmente, deconstruir los fundamentos incorporados y asimilados como naturales y verdaderos cuando, en el fondo, encubren injusticias y variadas formas de exclusiones.

Deconstrucción no significa negación, superación, tampoco simples inversiones de términos, situaciones o relaciones. No se trata de simplemente invertir las posiciones, transformando lo antiguo "dominado" en "dominador" o vice-versa. Para deconstruir, se hace necesario llevar al extremo cada dicotomía -mostrando que, en el límite, ella es falsa, porque fue construida como universal y natural a partir de concepciones e historias locales, que son siempre situadas y determinadas social y históricamente. (Derrida, 2001)

La estrategia de la deconstrución no es neutra: ella interviene. Es así que las diferencias no se diluyen inmediatamente en un caldo común, no son jerarquizadas, ni tratadas como superiores o inferiores, mejores o peores. Las diferencias permanecen en tensión, en ebullición, haciendo que con las mismas palabras, las mismas imágenes y los mismos símbolos no apenas produzcan diversas interpretaciones, pero, se mantengan ambivalentes. Y así preserven la flexibilidad, la posibilidad de continuar interactuando y cambiando, dislocando relaciones de poder.

Para Bhabha (1992), se trata de un espacio da resignificación, de la posibilidad de disolución de estereotipos y preconceptos y de empoderamiento, de fortalecimiento de autoconfianza y de la capacidad de acción de las personas y de los grupos populares. O sea, no podemos quedarnos en el lugar de víctimas. Al final, "a partir del momento en que hay una relación de poder, hay una posibilidad de resistencia. Jamás somos aprisionados por el poder: podemos siempre modificar su dominación en condiciones determinadas y siguiendo una estrategia precisa." (Foucault, 1979:241).

Practicar la deconstrución a favor de la reciprocidad requiere potencializar las paradojas e las contradicciones que culminan en la construcción de significados y procesos de subjetivación diversos y diferentes de los habituales, porque ellos son reconocidamente plurales y polisémicos. Eso implica, muchas veces, transgresión y subversión, materializadas como crítica y mudanza de los modos de entender, sentir y actuar. Esa transgresión, en general, puede significar una percepción de lo inusitado, de lo inesperado en nuestras acciones y relaciones, de lo diferente. Todo eso puede llevar a la reflexión y a tomar posición por el desplazamiento de significados cristalizados y carentes de crítica o reflexión (Aziribeiro, Fleuri, 2006), condiciones básicas para la solidaridad, reciprocidad y alteridad.

En esta dirección, es fundamental retomar algunas de las ideas de Paulo Freire ya que su pensamiento puede colaborar para abrir caminos en nuevas prácticas educativas transformadoras, en la dirección aquí anunciada.

Paulo Freire (1978) aclara que toda práctica educativa implica concepciones de seres humanos y de mundo, las cuales constituyen la energía que motiva y moviliza al hombre en alguna dirección. Este sujeto individual/colectivo es capaz de sentir, pensar y actuar críticamente, una vez que tiene claros sus puntos de partida y de llegada, estando dispuesto a construir y a reconstruir rutas de senderos que le permitan caminar continuamente -salvaguardando que no sea a pasos largos, rápidos y siempre exitosos. De esa forma, el 
educador llama la atención en las implicaciones producto de las creencias y de los valores que determinan la acción humana, resaltando la importancia de tener una percepción crítica de la realidad, con vistas a una acción transformadora.

Es que el proceso de orientación de los seres humanos en el mundo envuelve no apenas la asociación de imágenes sensoriales, como entre los animales, sino, sobre todo, pensamiento-lenguaje; envuelve deseos, trabajo-acción transformador sobre el mundo, del que resulta el conocimiento del mundo transformado. Este proceso de orientación de los seres humanos en el mundo no puede ser comprendido, desde una perspectiva puramente subjetivista; o desde otro ángulo objetivista mecanicista. La verdad, esta orientación en el mundo solo puede ser realmente comprendida en la unidad dialéctica entre subjetividad y objetividad. Así entendida, la orientación en el mundo pone la cuestión de la finalidad de la acción al nivel de la percepción crítica de la realidad. (Freire, 1978:4243).

Continua y cotidianamente son producidas diferencias de género, clase, etnia, generacionales y tantas otras más. Entender que esas diferencias no son dadas o naturales, sino, producidas relacionalmente es esencial para su re-significación constante. En segundo lugar, es necesario percibir que la identidad es relacional y producida, no precisando, por eso, ser cristalizada. "Las culturas, las expresiones culturales no son mejores ni peores, son diferentes entre ellas. Como nosotros, por otro lado, la cultura no es, está siendo." (Freire, Faundez, 1985:25)

En una perspectiva intercultural, la educación deja de ser asumida como un proceso de formación de conceptos, valores y actitudes a partir de una relación unidireccional, unidimensional y unifocal (conducida por procedimientos lineales y jerarquizantes), pasando a ser entendida como un proceso construido por la relación tensa e intensa entre diferentes sujetos, creando contextos interactivos (Fleuri, 2004). La educación está dinámicamente conectada con diversos contextos en relación a los cuales los diferentes sujetos desarrollan sus respectivas identidades. Es así que la educación se torna una posibilidad creativa y propiamente formativa, o sea, constructora de movimientos de identificación subjetivos y socioculturales.

El concepto de interculturalidad puede, por lo tanto, ser central para la re-construcción de un pensamiento crítico - otro -, un pensamiento crítico de/desde otra forma y lugar, precisamente por tres razones principales: (a) porque está vivido y pensado desde la experiencia de la colonialidad; (b) porque refleja un pensamiento no basado en los legados eurocéntricos o de la modernidad referenciada en una temporalidad única y establecida desde Europa, (c) porque tiene su origen en el "sur", dando así una vuelta a la geopolítica dominante del conocimiento que ha estado centrado en el "norte" global. (Walsh, 2001).

De este modo, la interculturalidad representa:

[...] un proceso dinámico y permanente de relación, comunicación y aprendizaje entre culturas en condiciones de respeto, legitimidad mutua, simetría e igualdad. Un intercambio que se construye entre personas, conocimientos, saberes y prácticas culturalmente diferentes, buscando desarrollar un nuevo sentido entre ellas en su diferencia. Un espacio de negociación y de traducción donde las desigualdades sociales, económicas y políticas, de las relaciones y los conflictos de poder de la sociedad no son mantenidos ocultos y si reconocidos y enfrentados. Una tarea social y política que interpela al conjunto de la sociedad, que parte de prácticas y acciones sociales concretas y conscientes que intenta crear modos de responsabilidad y solidaridad. (Walsh, 2001:10-11)

Enfatizar el carácter relacional e inter-contextual de los procesos sociales permite reconocer la complejidad, la singularidad, la diversidad, la polisemia, la fluidez y la relacionalidad de los fenómenos humanos y culturales, trayendo implicaciones importantes para varios campos, entre los cuales se destaca el ocio/educación comprometido con la transformación de realidades, volviéndolas más humanas, sostenibles y dignas para todos.

Freire (1978) expresa, como punto de partida para transformar la realidad, el análisis y comprensión crítica del hombre sobre sí mismo y sobre su contexto, como existentes en el mundo y con el mundo, dejando grabadas sus marcas distintivas, en su pensar, en su crear, en su actuar, en sus valores. Además de eso, 
estimula la necesidad de problematizar y superar las dicotomías que fuimos incorporando, pues, todas ellas traen implícita una relación de jerarquización. Al pensar en las relaciones mente/cuerpo, razón/emoción, hombre/mujer, blanco/negro, escrito/oral, norte/sur, occidente/oriente, por ejemplo, automáticamente se constata la situación de privilegio y de supremacía del primer término, en menoscabo del segundo.

Estas dicotomías, fragmentaciones y jerarquizaciones necesitan ser enfrentadas de modo urgente para que la transformación social y la construcción de un mundo más humano y solidario, que valore y respete la diversidad cultural, sea posible. Esto puede ser hecho a partir de muchos frentes, pero, la tesis que defiendo y acredito es que el ocio resignificado, problematizador, crítico, sinérgico y transformacional puede ser una (y no la única) herramienta importante para movilizar experiencias interculturales y educativas contrahegemónicas, contribuyendo así con un aprendizaje (educación) para la transformación social y cultural (Elizalde, 2010). Previamente, es fundamental deconstruir las creencias aquí discutidas, entre otras, que están arraigadas en la estructura condicionada y aprendida de cada ser humano y que impiden la movilización, el cuestionamiento y la resistencia al orden social injusto y excluyente que predomina en América Latina.

En esta perspectiva, el ocio se llena de un potencial significativo para enriquecer las prácticas educativas a partir de distintos lenguajes que pueden, desde una lógica diferente de la tradicional/excluyente, ampliar la comprensión sobre nosotros mismos y sobre el mundo en que vivimos. Por lo tanto, precisamos avanzar en la concepción y acción para que las prácticas recreativas sean también educativas desde una perspectiva crítica; para que una educación lúdica sea también problematizadora, transformadora y hasta subversiva, estando abierta a incluir diversos campos como: la familia, la sociabilidad, el arte, la cultura, el ocio, entre otros.

Como observan Gomes y Faria (2005), el ocio es uno de los hilos tejidos en la red humana de significados, símbolos e significaciones que debe ser pensado en el campo de las prácticas humanas como un entramado de sentidos y significados dialécticamente distribuidos en las construcciones subjetivas y objetivas de los sujetos, en diferentes contextos de prácticas sociales, culturales y educativas.

Constituido conforme a las peculiaridades del contexto histórico y sociocultural en el cual es desarrollado, el ocio implica producción de cultura -en el sentido de la reproducción, construcción e transformación de prácticas culturales vivenciadas lúdicamente por personas, grupos, sociedades e instituciones (Gomes, 2008). Esas acciones son construidas en un tiempo/espacio social, dialogan y sufren interferencias de las demás esferas de la vida en sociedad y nos permiten resignificar, simbólica y continuamente, la cultura.

En este artículo, el ocio es comprendido como una dimensión de la cultura caracterizada por la vivencia lúdica de manifestaciones culturales en el tiempo/espacio social. En cuanto producción cultural humana, el ocio es una práctica social compleja e históricamente determinada que constituye relaciones dialógicas con la educación, el trabajo, la política, la economía, el lenguaje, la salud, la ciencia y la naturaleza, entre otras dimensiones de la vida, siendo parte integrante y constitutiva de cada sociedad (Gomes, 2004).

Es importante aclarar que la ludicidad se refiere a la capacidad del homo ludens -en su esencia cultural dispuesta a jugar, imaginar, compartir, disfrutar, reír, emocionar- de elaborar, aprender y expresar significados. Cabe recordar que, desde el sentido común, las palabras lúdico y ludicidad son, de forma equivocada, asociadas exclusivamente a la infancia y son tratadas como sinónimo de determinadas manifestaciones de la cultura, principalmente las del juego. Esta interpretación puede ser ampliada, pues, las prácticas culturales no son lúdicas por sí mismas: ellas son construidas en la interacción del sujeto con la experiencia vivida, lo que puede abarcar diversas manifestaciones culturales.

Las manifestaciones culturales que constituyen el ocio son prácticas sociales vivenciadas como disfrute de la cultura, tales como: fiestas, juegos, paseos, viajes, música, poesía, grafiti y murales, pintura, escultura, danza, vivencias y expresiones corporales, fotografía, teatro, actividades comunitarias, ferias con nuevas modalidades de intercambio, actividades recreativas y deportivas, festivales y eventos artísticos, variadas modalidades de educación popular local, espacios de conversación y debate, entre muchas otras. 
Estas y otras manifestaciones poseen significados singulares para los sujetos que las viven. Son, así, prácticas inmemorables en la cultura de cada pueblo y pueden asumir múltiples significados: al ser concretizadas en un determinado tiempo/espacio social, al dialogar con un determinado contexto y, también, al asumir un papel peculiar para los sujetos, para los grupos sociales, para las instituciones y para la sociedad que las vivencia histórica, social e culturalmente.

En esa perspectiva la dimensión tiempo es inseparable de la dimensión espacial, y vice-versa, constituyendo un "tiempo/espacio social". Tal comprensión resalta la relevancia de problematizar las representaciones abstractas de las categorías tiempo e espacio. Santos (1980:206) señala que no es posible definir los acontecimientos históricos y espaciales "fuera de sus propias determinaciones o sin tomar en cuenta la totalidad de la cual ellos emanan y que ellos reproducen. El espacio social no puede ser explicado sin el tiempo social", concluye el autor. Este mismo autor (p.207) esclarece, además, que "la noción de tiempo es inseparable de la idea de sistema. En cada momento de la historia local, regional, nacional o mundial, la acción de las variables presentes depende estrictamente de las condiciones generales del sistema en que se sitúan."

El tiempo/espacio social es producido, por lo tanto, como condición de posibilidad de las relaciones sociales y de la naturaleza, a través de la cual la sociedad, al mismo tiempo en que se produce a sí misma, transforma la naturaleza y se apropia de ella (Lefebvre, 2008), o mejor dicho, se integra con ella. Por eso, el tiempo/espacio social de ocio corresponde a la apropiación del momento presente en un determinado lugar y no se limita a los períodos institucionalizados, más allá de que las condiciones concretas para que esto acontezca generalmente coincida con normas sociales formalmente adoptadas en cada contexto histórico. Así siendo, el tiempo/espacio es un producto de las relaciones sociales y de la naturaleza, constituido por aspectos objetivos, subjetivos, simbólicos, concretos y materiales, evidenciando conflictos, contradicciones y relaciones de poder.

Es así que el tiempo/espacio de ocio, por medio de diferentes experiencias, puede contribuir con la reelaboración de valores y caminar en dirección al proceso de re-construcción de nuestra sociedad por el prisma de la cultura. En cuanto una dimensión de la cultura, el ocio es un fenómeno que puede agudizar las sensibilidades (sensibilidad que está relacionada al plano sensorial, pero que debe ser también sensibilidad afectiva y no solo racional, artística, estética, ética, social, política, ecológica, etc.), ayudar a las personas a conectaren consigo mismas y con su contexto, estimular a pensar sobre las sociedades para transformarlas y reflexionar sobre aspectos más amplios.

En la opinión de Santos (2000), muchas prácticas culturales pueden constituir auténticas formas de ocio popular, representativas del pueblo haciendo cultura y, especialmente por eso, haciendo política. Así, el ocio también es política, pudiendo ser contrahegemónico y constituir una potente herramienta de cambios sociales.

El ocio puede comprometerse, así, con una educación subversiva, contrahegemónica e innovadora, capaz de transformar la realidad social en el sentido de tornarla más humana, equitativa, solidaria, digna, justa y sustentable. Cambio de mentalidad ya identificado hace mucho tiempo y ampliamente incorporado en el plano del discurso, pero, que necesita urgentemente volverse acciones concretas en la cotidianidad de las prácticas de ocio.

\section{Consideraciones finales}

Los conocimientos y las interpretaciones desarrolladas en este artículo son solamente una de las múltiples facetas que impulsan las miradas sobre el ocio y sobre la interculturalidad en América Latina. Esta región necesita de nuevas lecturas de sus historias. Hay que conocerlas y aprender desde ellas para construir estrategias de empoderamiento que posibiliten soñar con otros futuros, marcados por otras referencias donde la alteridad y la solidaridad sean realidades presentes en todos los campos de la vida cotidiana -incluso en el campo económico, que puede ser solidario, como muestran algunas experiencias de colaboración y reciprocidad que tienen importantes logros no difundidos por los medios masivos de comunicación (Moreno, 
2000). Realidades donde la democracia y la ciudadanía no sean solo palabras bonitas que adornan los discursos, sino prácticas y realizaciones concretas.

Por eso, es urgente y necesario construir otra realidad a partir de la transformación de mentalidades, de culturas y de procesos educativos y, como fue destacado, el ocio tiene un importante papel a desempeñar en este proceso de cambio.

Para eso, cada persona involucrada en el campo del ocio y de la recreación deberá incorporar su condición de sujeto histórico en su propio cotidiano. Esto solo puede ser concretizado por la vía del ocio problematizador, crítico y transformador, en contraposición a las prácticas recreativas estereotipadas, excluyentes, pasivas, consumistas y alienadas que claramente están comprometidas con la manutención del orden social establecido que corresponde a los intereses de los grupos privilegiados.

Desde el proceso de colonización y explotación los amerindios, por ejemplo, eran (des)calificados como ociosos y perezosos cuando la dificultad de trabajar era expresión de lucha, resistencia o imposibilidad corporal de llevar adelante el trabajo forzado, deshumano y esclavizado a que fueron sometidos, algo que lamentablemente aún ocurre, en muchos casos, en los días actuales.

En esta dirección, es necesario ampliar el conocimiento y la consciencia sobre las realidades que constituyen los pueblos de distintos países de la región latinoamericana como un solo pueblo. Además del destruidor huracán que hace poco destrozo completamente el Haití, poco se sabe sobre este país, que es uno de los más pobres de América Latina. Pero todos pueden aprender con ellos de su historia, ya que tienen el único proceso de independencia que, en esta región, no fue hecho por los privilegiados (criollos) nacidos en suelo americano para garantizar los intereses del capitalismo mercantil transnacional y de las oligarquías financieras nacionales. La independencia haitiana, la primera de América Latina, fue un largo proceso sangriento que dejó marcas profundas en el país, pero dejó también un ejemplo de lo que es una lucha movilizada por los propios intereses de las mayorías oprimidas. En el momento de las luchas por la independencia el Haití ya no tenía pueblos nativos porque los indígenas fueran completamente exterminados, pero tenía africanos esclavizados y sus descendientes con conciencia de que la libertad, la igualdad y la fraternidad reivindicada por la burguesía en Francia también deberían ser una realidad para ellos.

La historia oficial consagró los nombres de los "héroes" y las fechas que marcan las vitorias de los explotadores, pero poco aclara sobre quién fueron Túpac Amaru, Toussaint L'Overture, Miguel Hidalgo, José María Morelos, Manuel Rodriguez, Emiliano Zapata, José Artigas y Zumbi dos Palmares, entre tantos otros que fueron olvidados y sus hechos silenciados. Estos son algunos de aquellos que fueron destacados en la obra de Neruda (2005) porque lucharon por sus pueblos y sus culturas, y también por sus descendientes latinoamericanos.

De este modo, las siguientes preguntas son muy importantes: ¿Tenemos algo que aprender con las prácticas culturales de los pueblos indígenas aún existentes en la región latinoamericana? ¿Qué nos pueden enseñar las culturas afro-descendientes? ¿Tenemos algo que descubrir relacionado con sus modos de relacionarse con la tierra y con la naturaleza, con los tiempos/espacios sociales y con otros modos económicos que no son basados en la acumulación y en el lucro que beneficia solamente a algunos pocos? De igual modo, ¿Tenemos ideas, saberes y prácticas importantes para intercambiar con estos y con otros grupos desde una perspectiva intercultural? ¿Y qué papel jugaría en todo esto el ocio y la educación intercultural?

Es importante continuar repensando estas temáticas en el contexto latino-americano, pues sus análisis son inagotables, y su profundización e investigación pueden colaborar con la urgente necesidad de humanizar nuestras sociedades actuales (Gomes, Elizalde, 2009).

¿Será que esto es una quimera, un sueño imposible?

Las palabras que siguen, de Paulo Freire, pueden estimular acciones capaces de superar la postura pasiva, resignada, conformista, descontextualizada y alienada que avanza en todo el mundo y no solo en Latinoamérica. Por todo esto es necesario valorar la esperanza, el desafío y la disposición histórica para construir un mundo mejor: 
La conscientización nos invita a asumir una posición utópica frente al mundo, posición esta que convierte al conscientizado en "factor utópico". Para mi lo utópico no es lo irrealizable; la utopía no es el idealismo, es la dialectización de los actos de denunciar y anunciar, el acto de denunciar la estructura deshumanizante y de anunciar la estructura humanizante. Por esta razón la utopía es también un compromiso histórico. (Freire, 1980:27)

Así, es urgente y necesario encontrar nuevos caminos conceptuales y de acciones concretas que puedan contribuir con la construcción de un proyecto de sociedad comprometido con la emancipación del ser social y con la concretización de nuestras utopías comunes.

\section{Bibliografía}

Azibeiro, N. E.; Fleuri, R. M. (2006), Interculturalidade na educação popular e na formação de educador@s. In: Seminário Internacional Educación Intercultural, Movimentos Sociais e Sustentabilidade, 3; Colóquio da Association pour la Recherche Interculturelle (aric) na América Latina, 1, 2006, Florianópolis. Anais... Florianópolis: CED/UFSC. p. 01-24. ISBN: 85-87103-32-6. Disponible en: <http://www.rizoma3.ufsc.br/> Acceso el: 10/03/2010.

Bagú, S. (1993), Economía de la sociedad colonial. Grijalbo, México.

Bhabha, H. K. (1992), “A questão do ‘outro’: diferença, discriminação e o discurso do colonialismo”. En: Buarque de Holanda, H. Pós-modernismo e política. Rio de Janeiro, Rocco. p. 177-204.

Derrida, J. (2001), Posições. Autêntica, Belo Horizonte.

Dussel, Enrique (2000), “Europa, modernidad y eurocentrismo”. En: Lander, Edgardo (comp.) La colonialidad del saber: eurocentrismo y ciencias sociales. Perspectivas Latinoamericanas. CLACSO, Consejo Latinoamericano de Ciencias Sociales, Buenos Aires. Disponible en: http://bibliotecavirtual.clacso.org.ar/ar/libros/lander/dussel.rtf Aceeso el 30/03/2010

Elizalde, R. (2010), "Resignificación del ocio: Aportes para un aprendizaje transformacional”. En: Revista Polis. $N^{o}$ 25. Universidad Bolivariana, Santiago. Disponible em: http://www.revistapolis.cl/polis\%20final/25/art25.htm Acceso el 05/04/2010

Idem. (2008) El ocio entendido desde la teoría del desarrollo a escala humana: Buscando experiencias de aprendizajes para la transformación social. X Congreso Nacional de Recreación, Bogotá. Disponible en: http://www.redcreacion.org/documentos/congreso10/RElizalde.html Acceso el 02/04/ 2010.

Fleuri, R. M. (2004) “Intercultura e educación”. Revista Grifos: Dossiê Educación Intercultural. Chapecó/Santa Catarina, Argos. p.17-48.

Foucault, M. (1979) Microfisica do Poder. Graal, Rio de Janeiro.

Freire, P. (1978), Ação cultural para a liberdade. $3^{\circ}$ ed., Paz e Terra, Rio de Janeiro.

Idem. (1980), Conscientização: Teoria e prática da libertação. Moraes, São Paulo.

Freire, P.; Faundez, A. (1985), Por uma pedagogia da pergunta. Paz e Terra, Rio de Janeiro.

Gadotti, M. (2000), Pedagogia da Terra. $3^{\circ}$ ed., Fundação Petrópolis, São Paulo.

Galeano, E. (2009), As veias abertas da América Latina. $49^{\circ}$ ed., Paz e Terra, São Paulo.

Garcia Canclini, N. (1997), Culturas Híbridas: Estratégias para entrar e sair da modernidade. Edusp, São Paulo.

Goellner, S. et al. (2009), Gênero e raça: Inclusão no esporte e no lazer. Ministério do Esporte/Editora Gráfica da UFRGS, Porto Alegre.

Gomes, A. M. R.; Faria, E. L. (2005), Lazer e diversidade cultural. SESI/DN, Brasília. 
Gomes, C.; Elizalde, R. (2009), "Trabajo, tiempo libre y ocio en la contemporaneidad: Contradicciones y desafíos". In: Revista Polis. $N^{o}$ 22. Universidad Bolivariana, Santiago. Disponible en: http://www.revistapolis.cl/polis\%20final/22/art14.htm. Acceso el 30/04/2010.

Gomes, C. (2008), Lazer, Trabalho e Educação: Relações históricas, questões contemporâneas. $2^{\circ}$ ed. (rev. ampl.), Editora UFMG, Belo Horizonte.

Idem (2010), "O lazer como campo mobilizador de experiências interculturais revolucionárias e sua contribuição para uma educação transformadora". En: Dalben, Ângela; Diniz, Júlio; Leal, Leiva; Santos, Lucíola (Orgs.). Convergências e tensões no campo da formação e do trabalho docente: Currículo; Ensino de Educação Física; Ensino de Geografia; Ensino de História; Escola, Familia e Comunidade. Autêntica Editora, Belo Horizonte. p.284-310.

Idem (2004), "Lazer - Concepções”. In: Gomes, C.L. (Org.). Dicionário crítico do lazer. Autêntica Editora, Belo Horizonte. p. 119-126.

Grangeiro, L.H.F. (2009) Paulo Freire iluminando os caminhos da educação ambiental: Diálogos contemporâneos e decálogo inspirador e ressignificador de novas concepções e práticas. Palma de Mallorca, Universitat de Les Illes Balears (UIB). (Tesis de Doctorado). Disponible en:

http://www.tesisenxarxa.net/TESIS_UIB/AVAILABLE/TDX-1221109-142757//tlhfg1de1.pdf. Acceso el $02 / 03 / 2010$

Habermas, J. (2000), O discurso filosófico da modernidade. Publicações Dom Quixote. Portugal.

Hall, S. (2003), Da diáspora: Identidades e mediações culturais. Editora UFMG; Brasília, Representação da UNESCO no Brasil, Belo Horizonte.

Lander, E. (2000), “Ciencias sociales: saberes coloniales y eurocéntrico". En: Lander, E. (comp.) La colonialidad del saber: eurocentrismo y ciencias sociales. Perspectivas Latinoamericanas. CLACSO, Consejo Latinoamericano de Ciencias Sociales, Buenos Aires. Disponible en:

http://bibliotecavirtual.clacso.org.ar/ar/libros/lander/lander1.rtf Acceso el 12/03/2010.

Lefebvre, H. (2008), Espaço e Politica. Editora UFMG, Belo Horizonte.

Mignolo, W. (2000), "La colonialidad a lo largo y a lo ancho: el hemisferio occidental en el horizonte colonial de la modernidad". En: Lander, E. (comp.). La colonialidad del saber: eurocentrismo y ciencias sociales. Perspectivas Latinoamericanas. CLACSO, Consejo Latinoamericano de Ciencias Sociales, Buenos Aires. Disponible en: http://bibliotecavirtual.clacso.org.ar/ar/libros/lander/mignolo.rtf Acceso el 30/03/2010.

Moreno, A. (2000), "Superar la exclusión, conquistar la equidad: reformas, políticas y capacidades en el ámbito social". En: Lander, E. (comp.) La colonialidad del saber: eurocentrismo y ciencias sociales. Perspectivas Latinoamericanas. CLACSO, Consejo Latinoamericano de Ciencias Sociales, Buenos Aires, Argentina. Disponible en: http://bibliotecavirtual.clacso.org.ar/ar/libros/lander/moreno.rtf Acceso el 30/03/2010.

Neruda, P. (2005), Canto general. Santiago, Chile, Pehuén Editores.

Quijano, A. (2000), “Colonialidad del poder, eurocentrismo y América Latina”. En: Lander, E. (comp.), La colonialidad del saber: eurocentrismo y ciencias sociales. Perspectivas Latinoamericanas. CLACSO, Consejo Latinoamericano de Ciencias Sociales, Buenos Aires. Disponible en: http://bibliotecavirtual.clacso.org.ar/ar/libros/lander/quijano.rtf Acceso el 17/03/2010.

Santos, M. (1980), Por uma Geografia Nova - da crítica da Geografia a uma Geografia crítica. 2. ed. São Paulo, Hucitec.

Idem. (2000), "Lazer popular e geração de empregos". En: Serviço Social do Comércio/World Leisure and Recreation Association. Lazer numa sociedade globalizada/Leisure in a globalized society. SESC/WLRA, São Paulo. p.31-37.

Walsh, C. (2001), “¿Qué conocimiento(s)? Reflexiones sobre las políticas de conocimiento, el campo académico, y el movimiento indígena ecuatoriano"Boletín ICCI - "RIMAY". Instituto Científico de Culturas Indígenas. Año 3, $\mathrm{n}^{\mathrm{o}} 25$, Quito, abril de 2001 . 
Weber, M. (1973) $O$ político e o cientista. $2^{\circ}$ ed., Presença, Lisboa.

\section{Notas}

\section{- $\quad$ Apoyo: $\mathrm{CNPq}$ / FAPEMIG}

** Universidade Federal de Minas Gerais, Belho Horizonte, Brasil. E-mail: chrislucegomes@gmail.com. Este texto fue elaborado a partir de las ideas desarrolladas en la ponencia "Recreación, ocio e interculturalidad en América Latina". Esta ponencia fue presentada en el II Simposio Internacional de Recreación: "Ciudades Recreativas en América Latina: Políticas públicas, ciudadanía e interculturalidad", realizada en Medellín, Colombia, en abril de 2010

'En el texto se ocupará la palabra "ocio" (en español) como sinónimo de la palabra "lazer” en la lengua portuguesa hablada en Brasil. 